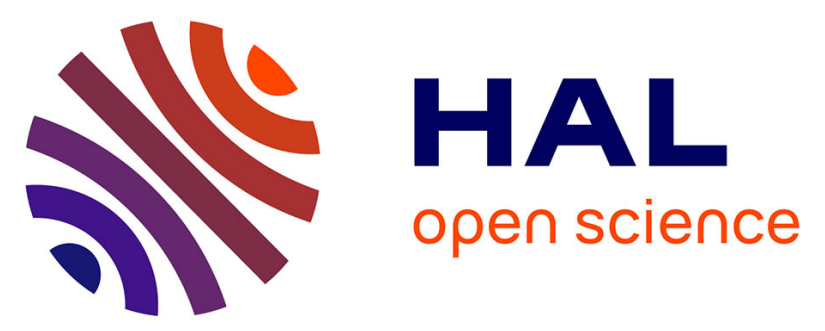

\title{
Full coverage infrared thermography diagnostic for WEST machine protection
}

X. Courtois, Mh. H Aumeunier, C. Balorin, J.B. B Migozzi, M. Houry, K. Blanckaert, Y. Moudden, C. Pocheau, A. Saille, E. Hugot, et al.

\section{- To cite this version:}

X. Courtois, Mh. H Aumeunier, C. Balorin, J.B. B Migozzi, M. Houry, et al.. Full coverage infrared thermography diagnostic for WEST machine protection. Fusion Engineering and Design, 2019, 146, pp.2015-2020. 10.1016/j.fusengdes.2019.03.090 . hal-02309494

\section{HAL Id: hal-02309494 \\ https://hal-amu.archives-ouvertes.fr/hal-02309494}

Submitted on 9 Oct 2019

HAL is a multi-disciplinary open access archive for the deposit and dissemination of scientific research documents, whether they are published or not. The documents may come from teaching and research institutions in France or abroad, or from public or private research centers.
L'archive ouverte pluridisciplinaire HAL, est destinée au dépôt et à la diffusion de documents scientifiques de niveau recherche, publiés ou non, émanant des établissements d'enseignement et de recherche français ou étrangers, des laboratoires publics ou privés. 


\title{
Full coverage infrared thermography diagnostic for WEST machine protection
}

\author{
X. Courtois ${ }^{\mathrm{a}, *}$, MH. Aumeunier ${ }^{\mathrm{a}}$, C. Balorin ${ }^{\mathrm{a}}$, J.B. Migozzi ${ }^{\mathrm{b}}$, M. Houry ${ }^{\mathrm{a}}$, K. Blanckaert ${ }^{\mathrm{a}}$, \\ Y. Moudden ${ }^{a}$, C. Pocheau ${ }^{a}$, A. Saille ${ }^{a}$, E. Hugot ${ }^{c}$, M. Marcos ${ }^{c}$, S. Vives ${ }^{a}$, WEST Team ${ }^{a}$ \\ ${ }^{\text {a }}$ CEA, Insvtitute for Research on Fusion by Magnetic confinement, 13108, Saint-Paul-Lez-Durance, France \\ ${ }^{\mathrm{b}}$ JBM Optique, 11 avenue de la division Leclerc, 92310, Sèvres, France \\ ${ }^{\mathrm{c}}$ Aix-Marseille Univ., CNRS, CNES, LAM, Marseille, France
}

\section{A R T I C L E I N F O}

\section{Keywords:}

Infrared thermography

Temperature monitoring

Plasma facing component

Safe operation

\begin{abstract}
A B S T R A C T
The WEST platform aims at testing ITER like $\mathrm{W}$ divertor targets in an integrated tokamak environment. To operate long plasma discharges, IR thermography is required to monitor the main plasma facing components by means of real time surface temperature measurements, while providing essential data for various physics studies.

To monitor the new divertor targets, the WEST IR thermography protection system has been deeply renewed, to match the new tokamak configuration. It consists of 7 endoscopes located in upper ports viewing the whole lower divertor and the 5 heating devices. Electronic devices and computers allow data storage of $\approx 3 \mathrm{~Gb} / \mathrm{s} \mathrm{IR}$ images and real time video frames processing at $50 \mathrm{~Hz}$ rate, to ensure the protection of the main plasma facing components during plasma discharges by a feedback control of the power injected by the heating systems.

Each endoscope provides 2 views covering 2 divertor sectors of $30^{\circ}$ (toroidally) and 1 view of a heating antenna. Each optical line is composed of a tight entrance window followed by a head objective which forms an image transported through the endoscope by a series of 4 optical relays and mirrors, up to a camera objective. Finally, 12 IR cameras specially developed for WEST environment capture the thermographic data, at the wavelength of $3.9 \mu \mathrm{m}$, with a $640 \times 512$ pixels frame size.

The paper describes the design constraints and diagnostic technologies: optics, mechanics, electronics, hard \& software, cameras. Tvhe laboratory characterization procedures (Modulation Transfer Function, slit response, calibration), and the measurement performance results are given (spatial resolution, temperature threshold). Finally, first results obtained during experimental campaigns in WEST are presented.
\end{abstract}

\section{Introduction}

\subsection{Context}

There is a compelling need for fusion machine protection to measure the surface temperature of Plasma Facing Components (PFC) in order to ensure their integrity and control plasma discharge injected power. This is the role devoted to infrared (IR) thermography.

Tore Supra (TS) was a Carbon-based limiter machine, operated with L-mode from 1988 to 2012. It has been upgraded to WEST, after 5 years of intensive work. WEST is now a full metallic environment tokamak, with an X-point divertor configuration. It is targeted at testing ITER like divertor prototypes made of actively cooled bulk tungsten units, in tokamak conditions during long pulse operation [1]. The divertor can be submitted to heat flux deposition in the range foreseen for ITER $\left(10-20 \mathrm{MW} / \mathrm{m}^{2}\right)[1]$. The first plasma occurred in WEST at the end of 2016.

IR monitoring was routinely performed is TS since the ' $90 \mathrm{~s}$, and with a real time processing since 2005 . This allowed plasma campaigns with long and high-power discharges for years. For WEST, the IR monitoring remains a priority to operate the machine safely, and to provide essential data for various physics studies involving high heat flux deposition on PFCs.

\subsection{Infrared thermography diagnostics on WEST}

The WEST IR thermography system consists of several different diagnostics which all share the same data processing and acquisition system.

The main machine protection diagnostic, which is the object of this

\footnotetext{
* Corresponding author.

E-mail address: xavier.courtois@cea.fr (X. Courtois).
} 
paper, is the result of a full refurbishment of the formers IR endoscopes used on TS. It consists of a set of 12 IR cameras mounted on 7 endoscopes located in the upper ports of the machine and viewing downward. It brings a full coverage of the lower divertor, the baffle leading edge and the 5 heating devices: 3 Ion Cyclotron Resonance Heating (ICRH) antennas and 2 Lower Hybrid Current Drive (LHCD) launchers.

New diagnostics were also developed for WEST: a wide angle tangential view of the inner chamber located in an equatorial port, a very high resolution view focused on the divertor with a $0.1 \mathrm{~mm}$ spatial resolution [2], and 2 complementary views of the divertor (direct view through a window) and of a LHCD launcher (tangential view through a fibre bundle).

This paper is focused on the set of 7 upper port endoscopes. The others diagnostics are described in [3].

\section{Diagnostic description}

\subsection{Location and lines of sight}

For machine protection, the main diagnostic is the set of 7 upper endoscopes spatially distributed on the machine upper ports, and covering the full lower divertor (with some overlap) plus the 5 heating systems. In that aim, each endoscope has 3 optical lines enabling 2 divertor views and 1 antenna view (Fig. 1).

Previously in TS, the endoscopes were located closer to the inner wall, where the upper divertor is now installed. Consequently the endoscopes were moved outward, and a direct view of the antennas was no longer possible since it would have led to a very low angle of incidence. Thus the endoscopes were spun $180^{\circ}$ and the antenna is now viewed through a deflecting mirror located in the inner wall. This had a strong impact on the optical design of the antenna view.

\subsection{Project constraints}

The major project constraint was to reuse or revamp as much as possible existing parts of the 7 former IR endoscopes which contributed to the success of TS operation for more than 12 years [4]. This challenge concerned only mechanics and optics. All electronic components, i.e. data processing and acquisition system were fully renewed. The foremost requirements and constraints on the design were the following:

- Spatial resolution $<10 \mathrm{~mm}$

- Real Time Monitoring: processing time $<100 \mathrm{~ms}$

- Wide temperature range up to $\mathrm{W}$ melting $\left(3400{ }^{\circ} \mathrm{C}\right)$

- Match with new machine configuration: new endoscopes location,

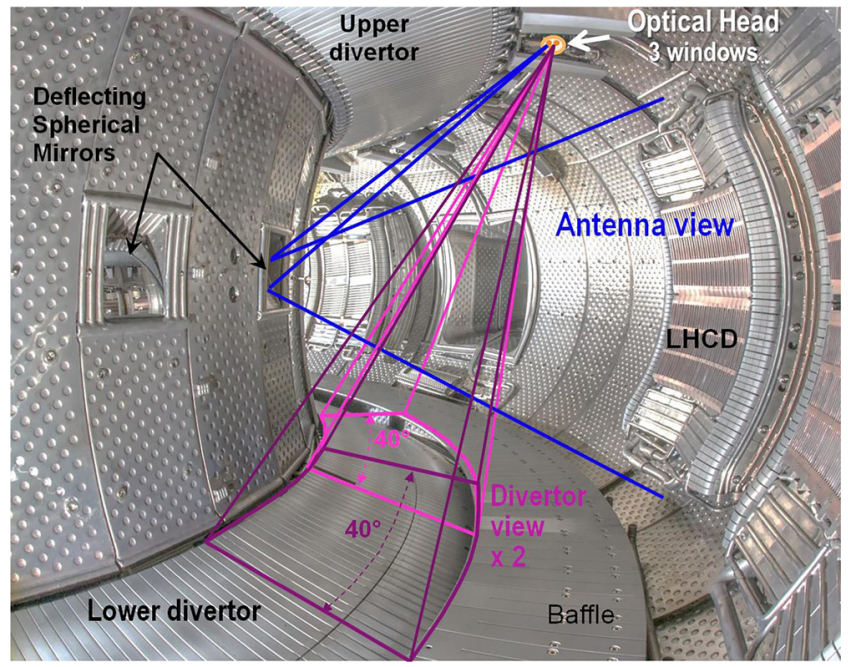

Fig. 1. upper port endoscope fields of view (FoV) in WEST.

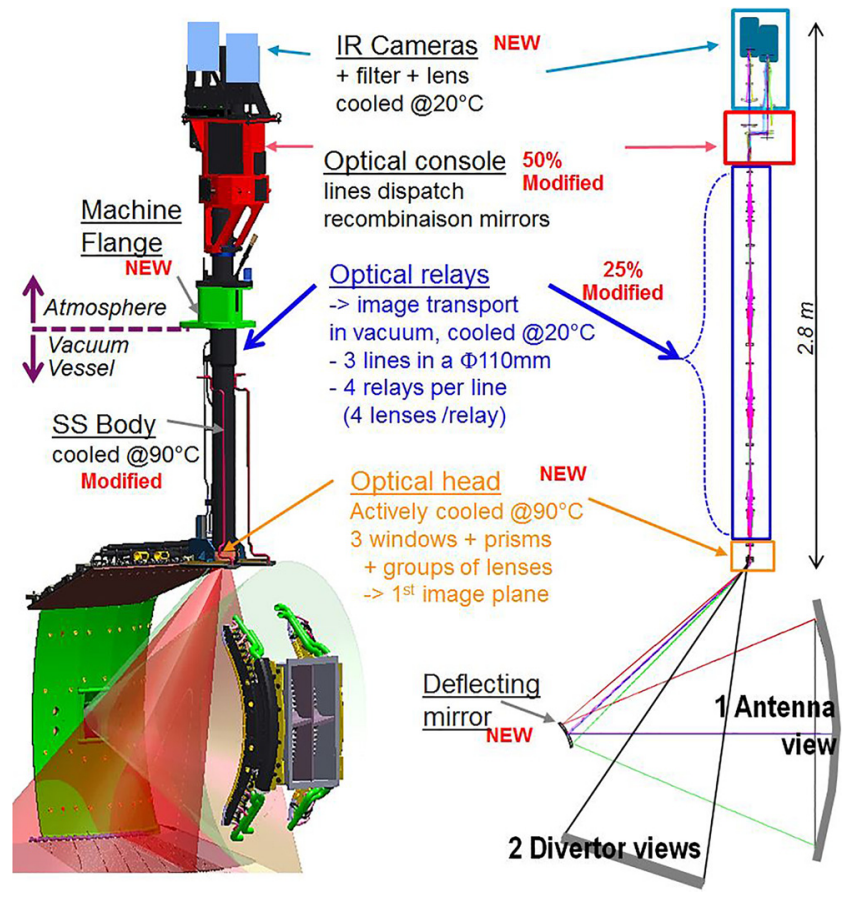

Fig. 2. Upper endoscopes for antennas and divertor views. Left $=$ engineering view, right $=$ optics principle.

new sight angles

- Withstand heat loads during long pulses, i.e. feature actively cooled plasma facing parts

\subsection{Refurbishment and design description}

The refurbishment of TS endoscopes lasted 3 years (2016-2018), including studies, manufacturing and assembling. Some modifications were required on the mechanics, flanges and bodies, to match new machine interfaces. The most important modifications concern the optics and opto-mechanics (Fig. 2). The modification of the optical design was done with ZEMAX software, at a wavelength of $3.9 \mu \mathrm{m}$, similarly to the former one, in order to keep as many lenses as possible unchanged. The new optical parameters are given in Table 1:

From bottom to top, the modifications concern:

\subsubsection{Deflecting mirror}

The deflecting mirror is a new component imposed by the endoscope relocation. It is a $170 \times 170 \mathrm{~mm}$ bulk molybdenum part, uncoated, with a convex spherical surface (radius of curvature $=250$ $\mathrm{mm}$ ). It was polished by conventional methods, with a roughness of $\approx 10 \mathrm{~nm}$, and spherical defect $<100 \mathrm{~nm}$ RMS.

The advantages of using Mo are a good erosion resistance [5] and a high conductivity ensuring homogeneous temperature and deformation fields. The drawback is a challenging polishing due to the toughness and fragility of the material. The mirror is mounted in a protecting niche, and screwed onto a supporting plate which is cooled by pressurized water flow. The maximum heat flux deposition on its surface for the most radiating plasma scenario $\left(130 \mathrm{~kW} / \mathrm{m}^{2}\right)$ leads to a maximum temperature of $200{ }^{\circ} \mathrm{C}$ (Fig. 3). At this temperature, the spherical

Table 1

Main optical parameters.

\begin{tabular}{llll}
\hline View & FoV & Aperture & Focale length \\
\hline Divertor & $48^{\circ}$ & F2.4 & $9.8 \mathrm{~mm}$ \\
Antenna & $9 \times 12^{\circ}$ (on mirror) & F3.6 & $45.7 \mathrm{~mm}$ (w/o mirror)
\end{tabular}



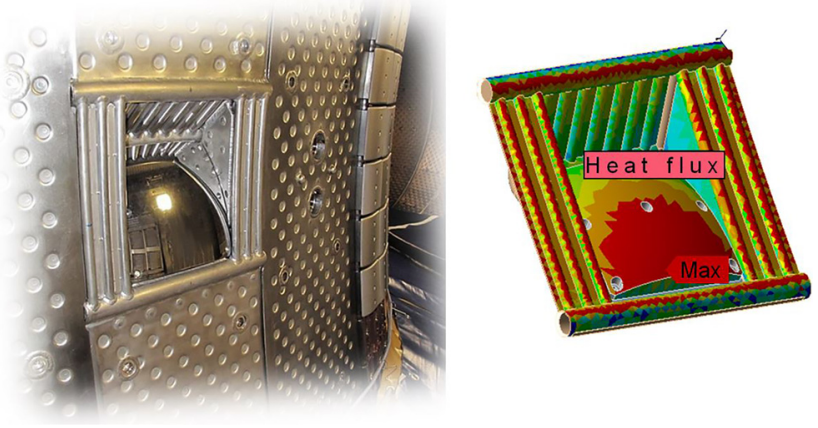

Fig. 3. Left: Mirror mounted in the inner wall of WEST - Right: calculated heat flux deposition pattern from plasma radiation $\left(\max =130 \mathrm{~kW} / \mathrm{m}^{2}\right)$.

surface deformation is in the order of the manufacturing tolerances, and the parasitic IR radiation increases the temperature of about $+10 \%$ for a target $@ 200{ }^{\circ} \mathrm{C}$, and $+3 \% @ 300{ }^{\circ} \mathrm{C}$ (luminance temperature) ; it is then considered acceptable, all the more this only concerns exceptional very high energy plasma scenario.

\subsubsection{Optical head}

In order to match the new FoVs and sight angles, a new optical head has been designed. A CuCrZr body ensures the protection (Fig. 4) from the incoming heat flux. It is cooled by pressurized water at machine temperature by inner channels to withstand up to $1.3 \mathrm{~kW}$ of plasma radiation. An additional front tube provides a shield against the electrons losses trapped in the magnetic field ripple propagating upward with a zigzag trajectory (up to $3 \mathrm{~kW}$ ). It is made of Nickel to offer high thermal conductivity and pressure resistance, while remaining easy to manufacture by bending. The 3 windows have a double sapphire disc: the first disc is brazed in a CuCrZr ring which is electron beam welded onto the body, and ensures the tightness. The second disc is held by a screwed washer. It protects the brazed disc in case of pollution, and can be easily replaced or cleaned during maintenance shutdown.

Behind the body is the optical part (Fig. 5). It consists first of 3 Silicone prisms which deviate the optical axis. Then a group of lenses makes the first image plane. Materials are $\mathrm{ZnSe}$, Ge or Si for lenses, peek for spacers and $\mathrm{Al}$ for mechanical parts. The lenses barrel is screwed and centered onto the prims cage. One divertor module lens is aspherical diffractive.

\subsubsection{Optical relays}

Each image formed by the optical head is propagated along the optical tube by 4 successive optical relays, with 4 lenses per relay, made of $\mathrm{Si}$ and Ge. This part is highly constrained by the $110 \mathrm{~mm}$ tube diameter, which leaves a maximum diameter of $36 \mathrm{~mm}$ for the lenses. The optical design effort allowed saving about $80 \%$ of the existing lenses, which was valuable given that lenses usually dominate the cost in an optical system. However, the disassembly and reassembly of some unchanged lenses were necessary, due to required modifications of opto-
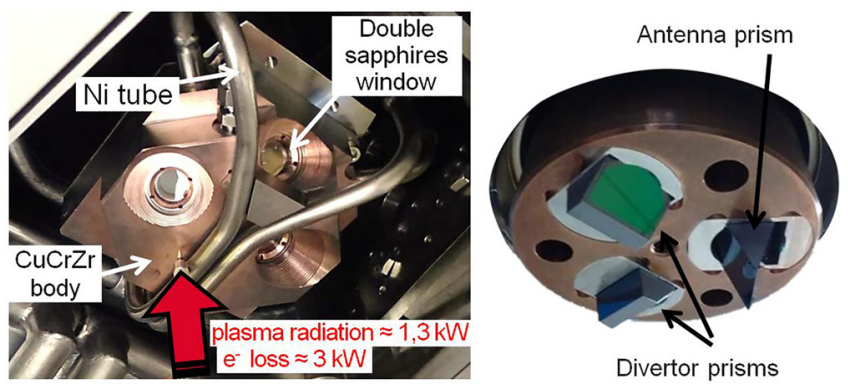

Fig. 4. picture of the optical head. Left = the body from inner vacuum vessel, Right $=$ front optics behind the body.

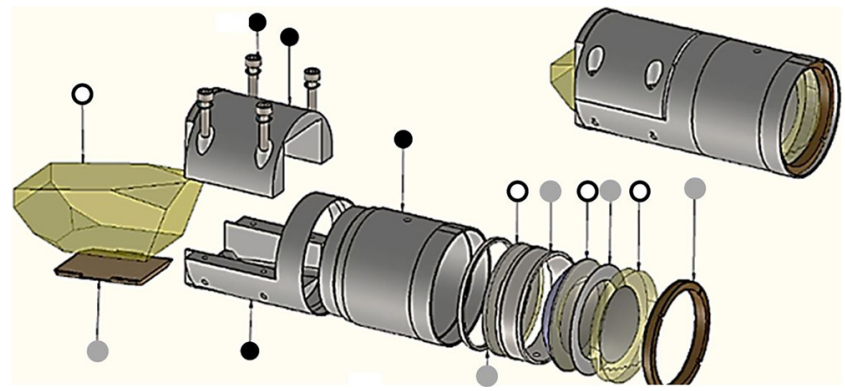

Fig. 5. Divertor first optical module: prims and lenses (white spots), spacers (gray spots) and mechanical assembling parts (black spots).

mechanical pieces, but with a low impact on manufacturing costs.

\subsubsection{Optical console}

The recombination console dispatches the antenna line on the first camera, and gathers the 2 divertor lines on the second camera, thanks to a set of flat gold coated silica mirrors. These mirrors also enable the differential focus adjustments. All the existing mirrors were degraded and have been replaced identically. However, the mechanical mounting of the mirror was significantly modified to adapt to the new sight angles.

\subsubsection{Camera}

12 homemade IR cameras based on InSb detectors were developed for this diagnostic (Fig. 6). These cameras are describes in [3]

\section{Temperature calculation and monitoring}

\subsection{Principle}

The temperature calculation procedure is similar to that used for TS [7], with the mirror as new component. It is performed in real time by a FPGA board (§3.2). It takes into account the laboratory camera calibration, and the transmission loss of all the optical lines. For this purpose, the optical system is divided in 3 independent parts, which are considered at different temperature: the mirror (for antenna view) @ $90{ }^{\circ} \mathrm{C}$, the optical head window @ $90^{\circ} \mathrm{C}$, and the optical relays and console @2 $2{ }^{\circ} \mathrm{C}$. The camera lens and the filter are taken into account in the camera calibration. The following calculation is performed in luminance: for each above mentioned optical part, starting by the top of the system (camera side), the parasitic signal radiated by the optical part (stray light) at its given temperature is subtracted to the luminance signal measured by the camera, and the transmission loss is then applied (i.e. the signal is divided by the transmission coefficient). The next optical part is calculated afterward. At the end, the estimated radiation luminance on the component is obtained and converted in temperature using the camera calibration curves.

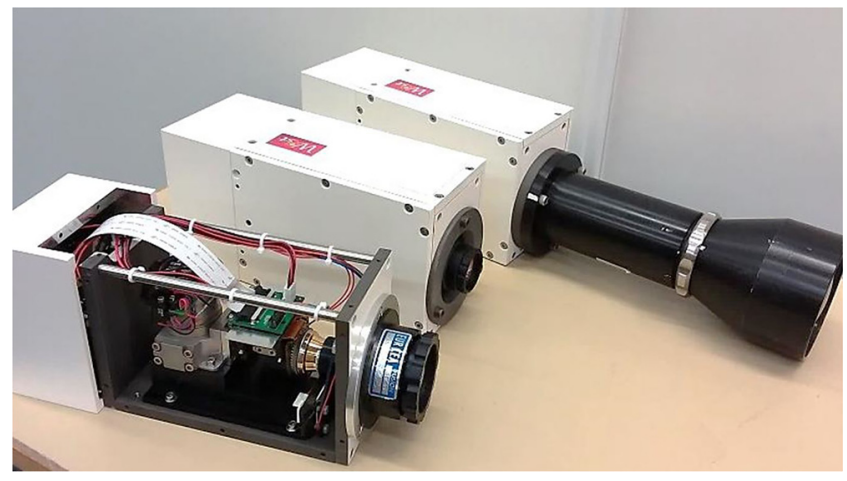

Fig. 6. Home-made cameras fitted with various lenses. 


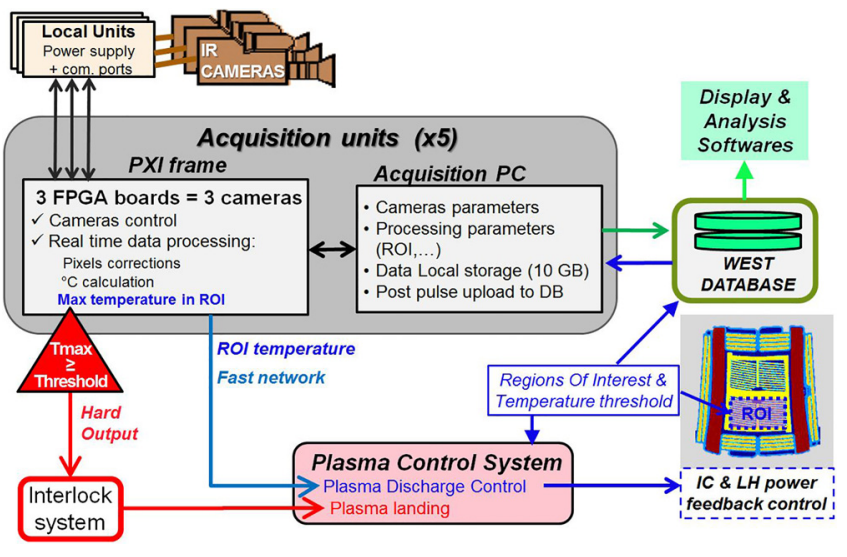

Fig. 7. data handling architecture.

Thanks to this method, cameras or optical relay tubes can be replaced or switched without recalibration of the full optical line since the calculation takes into account these parts individually. This method also gives practical advantages speaking calibration procedure (§4.1).

\subsection{Temperature monitoring}

The data architecture of the diagnostic is described in [3] and the data handling is resumed in (Fig. 7).

The maximum temperature in each predefined Region Of Interest (ROI) of the monitored components surface is passed via a fast network, to the Plasma Control System, which reduces the injected power when a temperature approaches the temperature threshold [6]. In case of overheating, a hard output flag is emitted to the interlock system which causes a soft plasma landing.

It is obvious that emissivity is a key parameter for IR temperature measurement. This parameter is a complex issue since emissivity may vary with temperature, surface roughness, material ageing and incidence angle. As a consequence, regarding real time machine protection, the temperature considered is always the luminance temperature, i.e. with emissivity $=1$. The temperature threshold applied in each ROI of the monitored components is the maximum acceptable temperature converted in luminance temperature. For a safe monitoring, the luminance temperature threshold is estimated with the lowest know emissivity of materials, which is initially determined either from bibliography, material test bed or experience. For example, the threshold is set at $600{ }^{\circ} \mathrm{C}$ for SS parts which corresponds to an utmost acceptable temperature of $1000{ }^{\circ} \mathrm{C}$ for a 0.3 emissivity.

For post pulse analysis, emissivity $<1$ can be applied on the IR data. Pre and post pulse analysis tools and detailed simulations are developed in parallel to better analyse and understand the impact of variable emissivity and reflections on measured temperature $[8,9]$.

\section{Laboratory characterization}

\subsection{Calibrations and optical transmissions}

All calibrations and optical transmissions are measured in laboratory at room temperature for each endoscope, using black bodies (BB), with similar the procedure as used for the former TS diagnostic [10]. The camera and its lens are calibrated separately, with a small BB featuring reference temperature up to $1600{ }^{\circ} \mathrm{C}$. Extrapolation is performed for higher temperatures, after taking into account the transmission calculation (§3.1), thanks to a good linearity of the detector. A dedicated test bed reproduces the machine configuration with divertor and antenna mock-ups and serves to tune the focus of the overall optical line, and adjust the mirrors for the correct recombination of the $2 \mathrm{di}$ vertor lines.
Table 2

Optical performances measured in lab. Note: vertical slit give horizontal resolution, and reciprocally.

\begin{tabular}{llll}
\hline Resolution (mm) & Pixel projection * & MTF 35\% & SRF 80\% \\
\hline Divertor Vert. & 2.7 & 9.4 & 5.4 \\
Antenna Vert. & 4.3 & 12.0 & 7.6 \\
Antenna Horiz. & 3.9 & 10.4 & 6.1 \\
\hline
\end{tabular}

* at MTF and SRF measurement location on Figs. 10 and 11.

A large $\mathrm{BB}$ covering the wide FoV of the divertor view is only necessary for transmission measurement at mid-temperature $\left(<400{ }^{\circ} \mathrm{C}\right)$. The total measured transmission coefficient in the field centre was measured at about 0.4 for the divertor view, and 0.3 for the antenna view, plus 0.76 for the double sapphires window.

The impact of in-situ operating temperature on signal is dealt by computations taking into account transmission coefficients and temperature of front-end optics $\left(90^{\circ} \mathrm{C}-120^{\circ} \mathrm{C}\right.$ for sapphire windows). Such temperature calculation and calibration methods make possible the calibration at laboratory room temperature. A post verification of the calibration process on the whole system discloses an overall accuracy of about $\pm 25^{\circ} \mathrm{C}$.

\subsection{Optical performances}

The optical performances can be expressed in different ways which are given here after. The optical performances are summarised in Table 2.

\subsubsection{Pixel resolution}

The pixel resolution is the projection of a pixel size in the object plane. It varies significantly for the divertor, due to the inclination of the line of sight from 2.3-5.6 mm/pixel. For antennas, values rank from 3.9 to $4.4 \mathrm{~mm} /$ pixel.

\subsubsection{Imaging spatial resolution}

The modulation transfer function (MTF) is a conventional method to characterize the response of an optical system, and gives the imaging spatial resolution.

The measured MTF is compared to the theoretical MTF which is the product of the optical MTF computed by ZEMAX and the MTF of the pixel size. The measured MTF (Fig. 8) is between the perfect case (all the lenses are perfectly machined and mounted) and the worst expected case (case for which the probability to have a bad combination of the tolerances, within those allocated for manufacturing and mounting, is less than 10\%), which is a satisfying result. The lowest acceptable imaging resolution is commonly done for $35 \%$ MTF, given in Table 2.

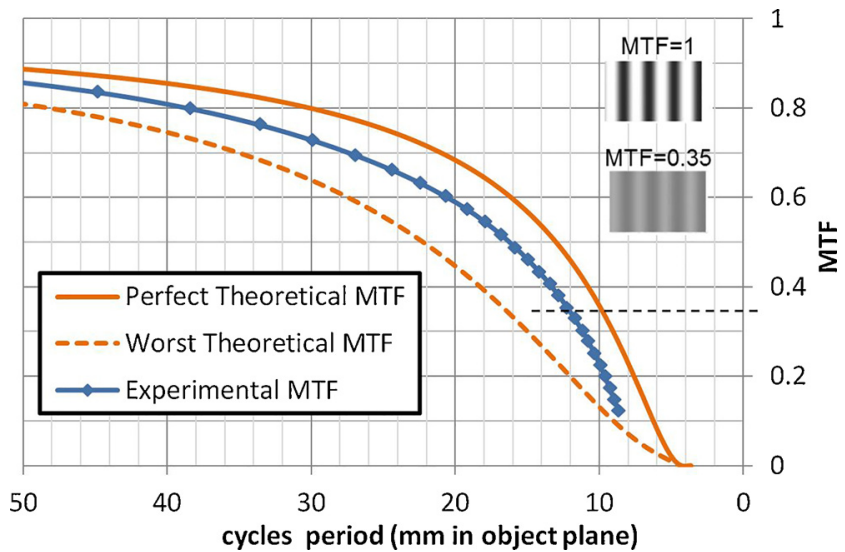

Fig. 8. Antenna view MTF for horizontal slit. A cycle is a black/white lines alternation (example: MTF $=1$ and 0.35 ). 


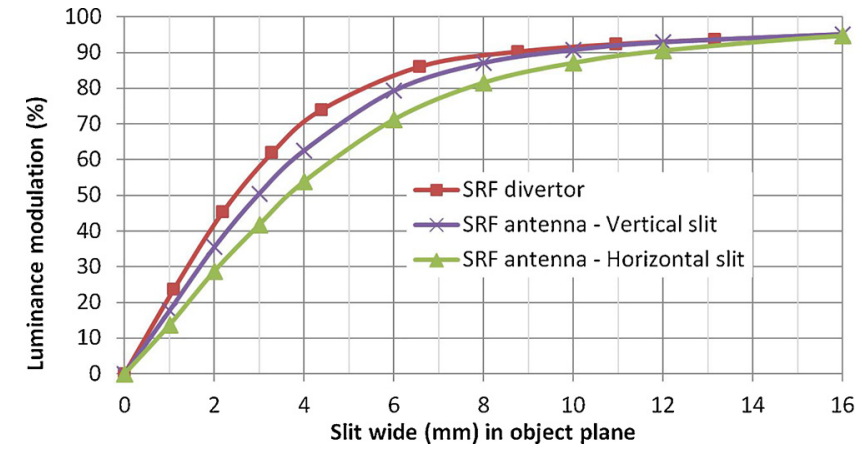

Fig. 9. Slit Response Function: luminance of a variable width slit which is illuminated from behind.

\subsubsection{Quantitative spatial resolution}

The MTF is inadequate to qualify thermal measurement performances; thus the Slit Response Function (SRF) was measured to quantify thermal spatial resolution (Fig. 9). This method allows determining the correction to be applied to the measurement of small objects which are spatially under-resolved. This is the case for example for the gaps between divertor targets, or thin plates between LHCD antenna wave guides.

For the divertor view, the horizontal and vertical directions (regarding the image aspect) are equal, which is not the case for the antenna view due to the deflecting mirror inclination. The SRF is given in Table 1 for $80 \%$ of luminance modulation which corresponds to a measurement error of $10 \% @ 1000{ }^{\circ} \mathrm{C}$, for a $3.9 \mu \mathrm{m}$ wavelength. This result is consistent with the theoretical SRF extracted from ZEMAX with an accuracy of less than $10 \%$ for antenna view, and $\approx 40 \%$ for divertor view. The latter is probably the result of a defocus due to an imperfect adjustment of console mirrors.

These results are in line with the project requirements.

\subsubsection{Minimum measurable temperature}

The minimum measurable level is determined for a level significantly higher than the background noise, typically 100 Digital Level. This level is approximately $150{ }^{\circ} \mathrm{C}$ for the divertor view and $200{ }^{\circ} \mathrm{C}$ for the antenna view. Images can be observed under these thresholds, but the temperature measurement is not reliable, i.e. the uncertainty increases significantly due to stray light and uncertainties due to calibration.

\section{Plasma operation and first results}

The system was under operation early 2018, with 2 endoscopes providing 2 antenna views and 4 divertor views; it is planned to be fully installed mid-2019. The figure Fig. 10 shows 2 divertor views recombined on one detector. They are in good qualitative agreement with simulations of heat load deposition on the WEST divertor using the PFCflux code [11]. The periodic pattern corresponding to WEST magnetic field ripple ( 1 toroidal coil per $20^{\circ}$ [12]) is clearly visible.

The figure Fig. 11 presents an IR image of an ICRH launcher during a disruption. The IR signal mainly comes from the wide spectrum plasma radiation reflecting on the metallic surfaces.

\section{Conclusion}

The IR system for WEST is a set of diagnostics dedicated to PFCs protection and machine operation, but it is also an essential support to physics investigations.

Seven endoscopes located in upper ports viewing the whole lower divertor and the 5 heating systems have been upgraded and manufactured. Their optical performances are in line with project and design requirements. The endoscopes are progressively installed on WEST. The

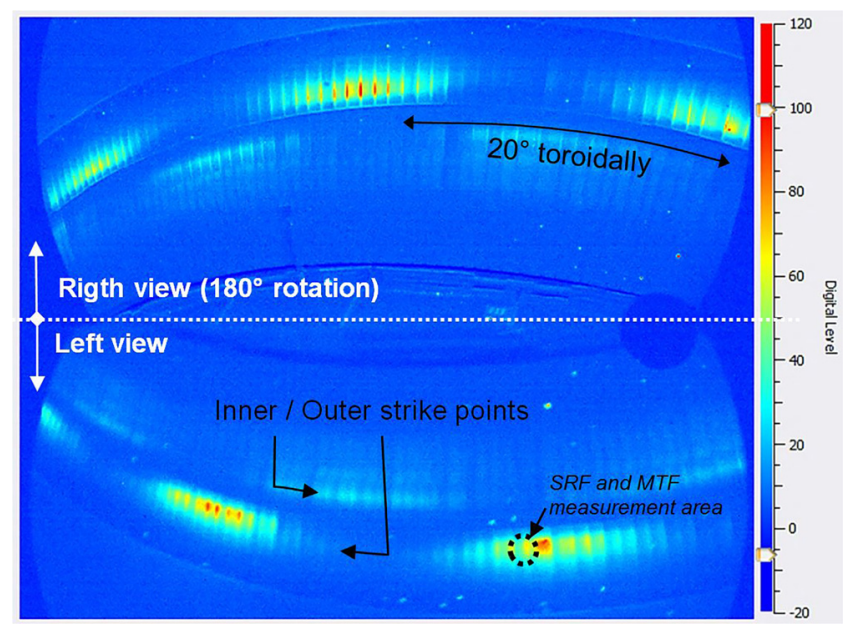

Fig. 10. Port 6 divertor IR image during pulse \#53,223 (LH + IC power $=2+0,6 \mathrm{MW} \mathrm{Ip}=500 \mathrm{~kW}$ ). Color scale is the luminance in arbitrary unit.

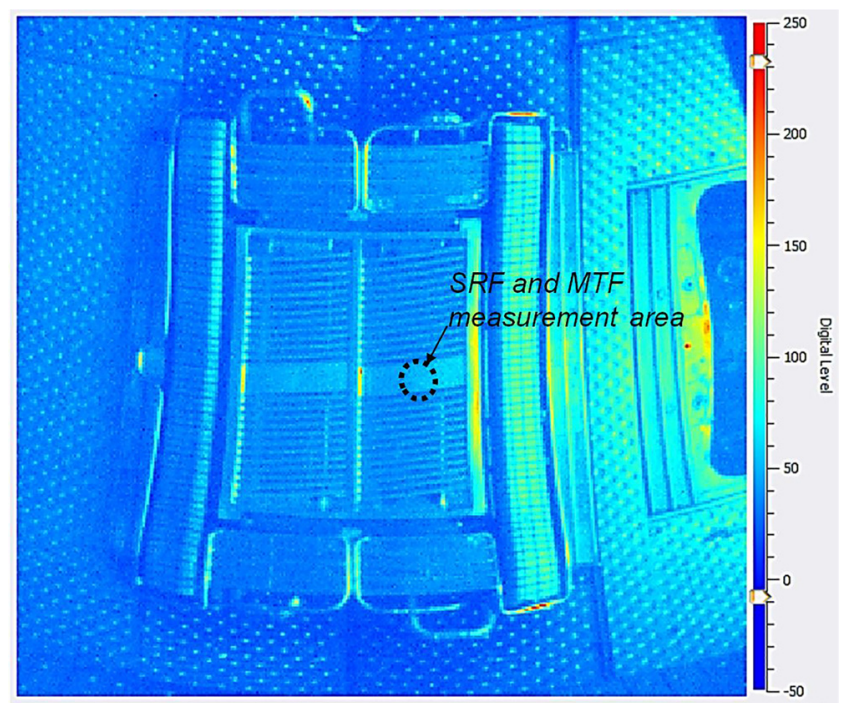

Fig. 11. Port 2 ICRH antenna IR image during pulse \#53,132 on plasma disruption. Color scale is in arbitrary unit.

total renewing of the cameras and of the data processing and acquisition system is achieved and gives satisfying results in operation.

Some upgrades are foreseen

- Manufacturing new camera lenses for divertor view to enhance the resolution

- Developpment of an embedded black body on WEST articulated inspection arm for in-situ calibration under vacuum and temperature conditions.

- Improvement of temperature calculation by measuring automatically the first optics temperature during pulses.

- Development of an inovative machine protection software to optimise the safe operationnal domain.

\section{Acknowledgments}

This work has been carried out within the framework of the EUROfusion Consortium and has received funding from the Euratom research and training programme 2014-2018 under grant agreement No633053. The views and opinions expressed herein do not necessarily reflect those of the European Commission. 


\section{References}

[1] J. Bucalossi, et al., Fusion Eng. Des. 89 (2014) 907-912.

[2] M. Houry, et al., To be published in SOFT- $30^{\text {th }}$ conference proceeding, Fusion Eng. Des. (2019).

[3] X. Courtois, et al., Fusion Eng. Des. 136 B (2018) 1499-1504.

[4] D. Guilhem, et al., Fusion Eng. Des. 74 (2005) 879-883.

[5] B. Eren, et al., J. Nucl. Mater. 438 (SUPPL) (2013) S852-S855.
[6] P. Moreau, et al., Fusion Eng. Des. 82 (2007) 1030-1035.

[7] D. Guilhem, et al., OIRT J. 2 (2005) 77-96.

[8] M.H. Aumeunier, et al., Rev. Sci. Instrum. 81 (2010) 10 E524.

[9] M.H. Aumeunier, et al., Nucl. Mater. Energy 12 (2017) 1265-1269.

[10] C. Desgranges, et al., Nuclear. Ints. \& Methods in Physics Research, A 879 (2018) 121-133.

[11] M. Firdaouss, et al., Fusion Eng. Des. 98-99 (2015) 1294-1298.

[12] R. Mitteau, et al., Fusion Sci. Technol. 56 (3) (2009) 1353-1365. 